\title{
ISOLAMENTO DE AMEBAS DE VIDA LIVRE A PARTIR DE ÁGUA MINERAL ENGARRAFADA *
}

Homero Coutinho Salazar ** Hercules Moura **

Ruth Tramontanj Ramos**

\begin{abstract}
SALAZAR, 11. C. et al. Isclamento de amebas de vida livre a partir de água mineral engar rafada. Rev. Saúde públ., S. Paulo, 16:261-7, 1982.

RESUMO: Foram isoladas amebas dos gêneros Vahlkampfia, Glaeseria, Acanthamoeba, Filamoeba, Amoeba, Platyamoeba e Hartmanella de dez diferentes marcas de água mineral engarrafadas, servidas no Rio de Janeiro, RJ (Brasil). Somente uma das marcas foi negativa para protozoários, enquanto que de todas as outras foram isoladas amebas de vida livre. $O$ significado desses resultados é discutido como um indicador de qualidade da água mineral usada comercialmente, destacando-se o fato de que alguns desses microorganismos são potencialmente patogênicos
\end{abstract}

UNITERMOS: Āguas minerais. Āgua, microbiologia, Amebas.

\section{INTRODUCAO}

Nos anos recentes, o reconhecinento do papel exercido pelos protozoários de vida livre nos problemas de contaminação das águas potáveis tem gerado maior interesse no seu estudo (Corliss ${ }^{\circ}, 1973$ ). Ortiz e Ochoterena $\because$ (1979) isolaram inúmeros protozoários da água distribuida à população da cidade do México e, entre eles, oito espécies de amebas de vida livre, sendo duas da familia Vahlkampfiidae.

Alguns desses microrganismos podem agir como patogênicos facultativos, causando meningoencefalite em animais de laboratório (Culbertson e col.7.8.9, 1958, 1959 e 1965) e em seres humanos. Os primeiros casos da doença hoje conhecida cono menin- goencefalite amebiana primária (MEAP) foram descritos por Fowler e Carter 1: (1965) na Austrália e por Butt ${ }^{1}$ (1966) nos EUA. Hoje mais de cem casos estão registrados na literatura (Thong e col.36, 1978), que aponta as amebas dos gêneros Naegleria e Acanthamoeba, respectivamente, Fertencentes às familias Vahlkampfiidae $\mathrm{e}$ Acanthamoebidae (Page 27,28, 1967. 1974). como responsáveis pela doença.

Estes protozoários são encontrados no solo e na água (Page 29,1976 ), com o eventual achado de amostras virulentas a partir desses locais (Culbertson e col.9 1965; Singh e Das ${ }^{35}$, 1970; Jadin e col.20, 1971 e Cerva 4, 1971). Amebas potencialmente

* Trabalho financiado parcialmente pelo Conselho Nacional de Desenvolvimento Científico a Tecnológico (CNPq). Processo n $n^{\circ} 40.0623 / 79$.

** Da Disciplina de Parasitologia do Departamfito de Patologia e Laboratórios da Faculdade de Ciências Médicas da Universidade do Estado do Rio de Janeilo - Rua Teodoro da Silva, 48. 5' - 20560 - Rio de Janeiro. R.J - Brasil 
SALAZAR, H.C. et al. Isolamento de amebas de vida livre a partir de água mineral engarrafada. Rev. Saúde puibl., S. Paulo, 16:261-7, 1982.

patogênicas foram também isoladas do ar e da poeira de um quarto ocupado por crianças acometidas de infecção respiratória (Kingston e Warhurst 22, 1969).

No Brasil, apesar de já ter sido descrito um caso de doença humana (Campos e col.2, 1977), poucos são os relatos da presença de amebas limax no ambiente. Foronda 11,15,16, (1974, 1976, 1979) isolou amebas de vida livre da água de um açude, im São Paulo, provável fonte de infecção de paciente com meningoencefalite. Além disso, a autora isolou estes protozoários da água da rede de distribuição pública e co lodo de piscinas.

Salazar * isolou, nos anos de 1978 e 1979. amebas dos gêneros Naegleria e Acanthamoeba, na cidade do Rio de Janeiro, a partir de diversas coleções de água. Moura 25 (1980) a partir de piscinas de clubes da cidade do Rio de Janeiro, isolou diversos gêneros de amebas de vida livre, sendo que algumas amostras apresentaram moderada ação patogênica para camundongos.

Em estudo anterior (Ramos e col. ${ }^{32}, 1980$ ) haviamos comprovado a presença de amebas de vida livre em amostras de uma única marca de água mineral muito vendida no Rio de Janeiro.

No presente trabalho tivemos como ubjetivo estudar a presença desses protozoários em diferentes marcas de água mineral distribuidas comercialmente nessa cidade.

\section{MATERIAL E MÉTODOS}

Foram examinadas amustras de dez marcas de água mineral, dentre as mais lacilmente encontradas no comércio da cidade do Rio de Janeiro. Cada marca foi identificada por uma letra, de $A$ a $J$, e as amostras incluiram águas do tipo natural e gasosa, estando algumas em frascos de vidro e outras em embalagem de plástico.

As marcas $B, C, E, l$ e $J$ estavan todas em frascos de vidro e eram do tipo gasosa. As amostras de água mineral $A$ e $D$ estavam contidas em frascos de vidro e as correspondentes às letras $F, G$ e $H$ eram também naturais, mas embaladas em plástico.

De cada marca foram examinados dez. litros, adquiridos de uma só vez em um mesmo estabelecimento comercial.

A pesquisa foi feita filtrando-se um litro por dia, de modo que tudo o volume da amostra era processado num prazo máximo de duas semanas. Empregou-se o filtro a vácuo Millipore com membrana de $50 \mathrm{~mm}$ de diâmetro e porosidade de $1,2 \mu \mathrm{m}$.

Após a filtração, a membrana era cortada ao meio e cada pedaço era colocado. com a face filtrante para baixo, em placas de Petri contendo agar não nutriente com algumas gotas de suspensão de Enterobacter cloaceae. Uma das placas era então incubada a $37^{\circ} \mathrm{C}$ e a outra deixada à temperatura do laboratório.

Foram consideradas negativas as placas sem crescimento até o $20^{\circ}$ dia de cultivo.

A metodologia seguida para cultivo, isolamento e identificação das amostras for aquela descrita por Molet e Kremer"4 (1976) e Page 29,30 (1976), com as modificações citadas por Moura 25 (1980).

\section{RESULTADOS}

$\mathrm{Na}$ Tabela 1 verificamos que foram isolados oito diferentes gêneros de amebas de vida livre, sendo que Acanthamoeba e Hartmanella estiveram presentes em seis das dez marcas pesquisadas.

A marca $F$ permitiu o isolamento de cinco gêneros de amebideos, enquanto que as marcas $A, C, D$ e $J$ foram positivas para quatro gêneros. Com menor número de representantes as marcas $B, E$ e $l$ (dois gêneros) e a amostra $H$, da qual se isolou um representante do gênero Hartmanella.

Protozoários ciliados do gênero Paramecium foram repetidamente isolados da água mineral $I$.

Somente a água mineral cuja marca corresponde à letra $G$ foi negativa para amebas de vida livre.

\footnotetext{
- Dados inéditos.
} 


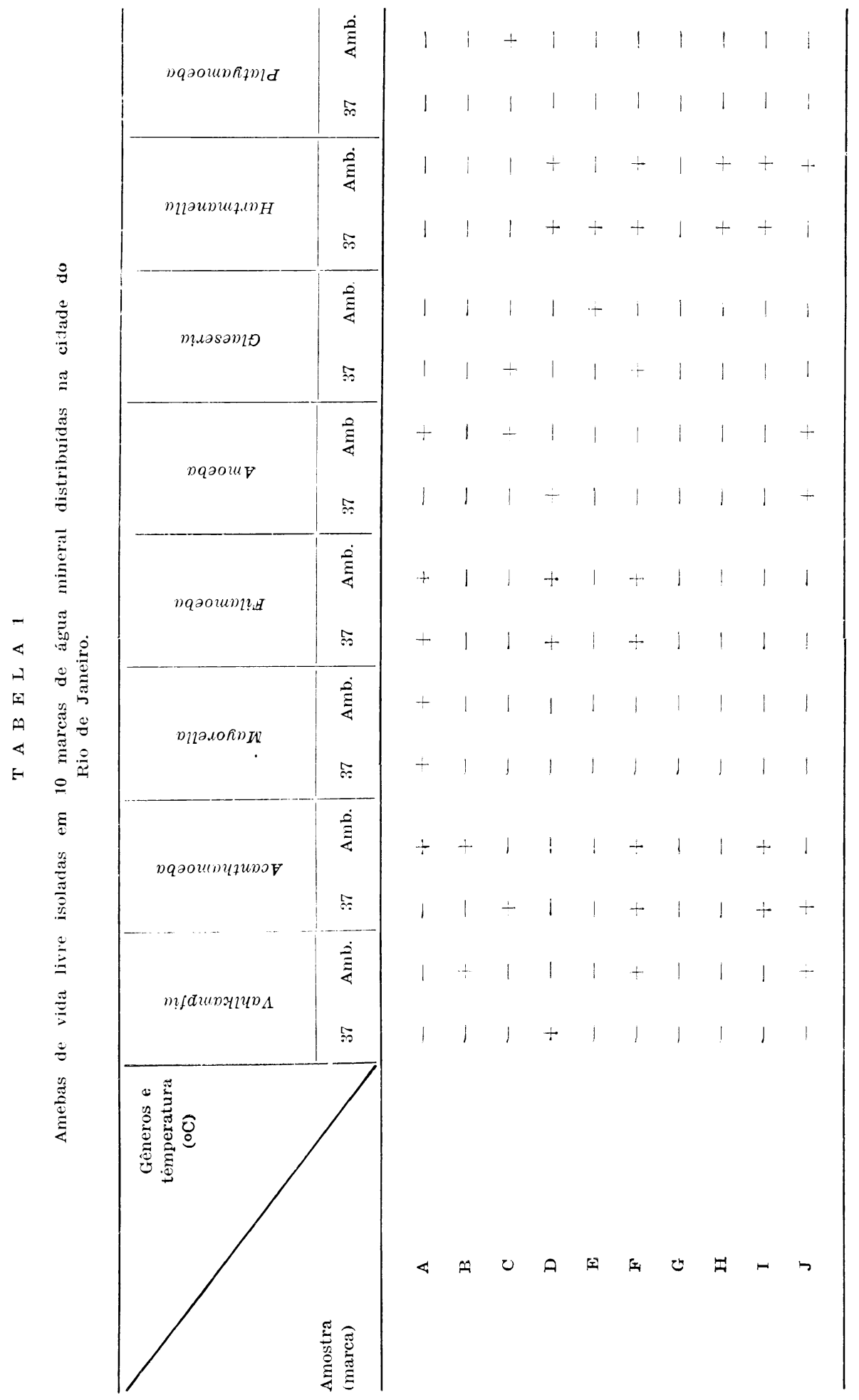


SALAZAR, H.C. et al. Isolamento de amebas de rida lirre a partir de água mineral engarrafada. Rev. Saúde públ., S. Paulo, 16:261-7, 1982.

Os gêneros isolados cresceram ben tanto à temperatura ambiente como a $37^{\circ} \mathrm{C}$, com a exceção da única amostra de Platyamoeba isolada, que só se desenvolveu na placa deixada à temperatura do laboratório.

A Tabela 2 mostra o percentual de placas positivas, verificando-se as marcas que apresentam maiores indices de contaminação. Esses niveis são quase sempre mais elevados nas placas em que o cultivo foi feito à temperatura do laboratório.

T A B E L A 2

Percentagem de placas positivas para cada marca e temperatura de cultivo.

\begin{tabular}{l|cr}
\hline \multirow{2}{*}{$\begin{array}{c}\text { Amosta } \\
\text { (marca) }\end{array}$} & \multicolumn{2}{|c}{$\begin{array}{c}\text { Percentagem } \\
\text { de placas positivas }\end{array}$} \\
\cline { 2 - 3 } & $\begin{array}{l}\text { Temperatura } \\
\text { ambiente }\end{array}$ & $370 \mathrm{C}$ \\
\hline $\mathrm{A}$ & 70 & 30 \\
$\mathrm{~B}$ & 20 & 0 \\
$\mathrm{C}$ & 20 & 20 \\
$\mathrm{D}$ & 100 & 80 \\
$\mathrm{E}$ & 20 & 10 \\
F & 100 & 100 \\
$\mathrm{G}$ & 0 & 0 \\
$\mathrm{H}$ & 40 & 20 \\
$\mathrm{I}$ & 10 & 10 \\
$\mathrm{~J}$ & 40 & 30 \\
\hline
\end{tabular}

\section{DISCUSSAO}

$O$ isolamento de amebas de vida livre a partir de águas de abastecimento de cidades e de água mineral tem sido relatado nos anos recentes, principalmente na literatura belga (Jadin e col.21, 1972), francesa (Paix 31,1974$)$ e recentemente nas américas (Ramos e col.32, 1980; Rivera e col.3", 1981).

Examinando diferentes marcas de água mineral vendidas na cidade do Rio de Janeiro, verificamos que $90 \%$ das amostras permitiram o isolamento de protozoários, sendo que $60 \%$ delas foram positivas para amebas do gênero Acanthamoeba.

Oito diferentes gêneros de amebideos foram identificados nas dez marcas estu- dadas, sendo que Vahlkampfia, Mayorella, Filamoeba, Glaeseria, Amoeba, Platyamoeba e Hartmanella ainda não haviam sido anteriormente assinalados em águas minerais.

Uma das amostras (I), da qual foram isolados protozoários do gênero Paramecium. deve ser relacionada com matéria orgânica em decomposição (Ortiz e Ochoterena 2", 1979; Corliss ", 1973), o que caracteriza a água como imprópria para o consumo.

Esses niveis de contaminação não deveriam ocorrer em águas servidas à população e provavelmente são devidas à falta de tratamento da água a ser engarrafada, pois os achados correspondem a levantamentos feitos em locais onde fatores diversos podem, ocasional ou permanentemente, contribuir para aumento da população microbiana.

Os resultados das marcas $F$ e $G$, ambas embaladas em plástico, reforçam a hipótese de contaminação no local da colheita, de vez que os frascos de $F$ apresentaram $100 \%$ de positividade, enquanto que os de G foram negativos em todos os cultivos.

A gaseificação parece não ter influenciado na positividade das amostras, o que já fora relatado em estudos feitos por Paix ${ }^{31}$ (1973), na Europa, ao encontrar resultados semelhantes em águas minerais e gasosas.

As marcas de água mineral com $100 \%$ de positividade, como $D$ e $F$, apresentaram nas placas de isolamento maior concentração de protozoários, enquanto que os frascos rotulados como $B, C$ e $E$ apresentaram, proporcionalmente, menor número de microrganismos.

Quanto à temperatura de cultivo, a incubação a $37^{\circ} \mathrm{C}$ parece ter sido fator limitante para melhor se poder avaliar o nível global de contaminação por amebas de vida livre. Entretanto, como as amostras patogênicas até agora isoladas crescem bem a $37^{\circ} \mathrm{C}$, esta temperatura pode ser usada visando $o$ isolamento seletivo de amostras potencialmente patogênicas (Griffin $1 s, 1972$ ).

Dentre as amebas isoladas, somente no zênero Acanthamoeba são encontrados representantes patogênicos. O fato de não 
SALAZAR, H.C. et al. Isolamento de amebas de vida livre a partír de água mineral engarrafada. Rev. Saúde públ., S. Paulo, 16:261-7, 1982.

termos isolado nenhuma amostra de Naegleria não afasta a possibilidade de sua presença nessas águas, de vez que o habitat desse gênero é o mesmo dos outros protozoários que conseguimos isolar.

Por outro lado, como o principal alimento das amebas de vida livre são microorganismos, fica claro que elas aumentam em número com a contaminação bacteriana. Dangeard 11 (1910), cita que "não existem amebas sem a presença de bactérias", afirmação que reforça a importância desses resultados como indicadores do grau de contaminação das águas minerais examinadas.

Ainda que a manifestação de patogenicidade dessas amebas esteja quase sempre relacionada com episódios de meningoencefalite fatal (Willaert 37,1977 ), um caso de disenteria aguda foi descrito por Metha e. Guirges ${ }^{23}$ (1979) em que o agente etiológico seria uma ameba do gênero Acanthamoeba. Ainda não existem, entretanto, evidências concretas para que possamos afirmar que a ingestão desses protozoários possa causar doença (Carter ${ }^{3}, 1968$, Chang ${ }^{5}$, 1979 e Cursons e col.10, 1979).

Devemos considerar também que bactérias e particulas virais foram identificadas no citoplasma e no núcleo dessas amebas (Schuster ${ }^{34}$, 1969; Dunnebacke e Schuster $12,13,1974,1977$ ), que poderiam agir como veiculadores de agentes patogênicos. Além disso, Jadin e Willaert ${ }^{19}$ (1977) comprovaram a viabilidade do Mycobacterium vaccae obuense, entre outras espécies do mesmo gênero, que havia sido fagocitado por amebídeos.

\section{CONCLUSÕES}

O isolamento de diversas amostras de amebas de vida livre em 9 entre 10 marcas de água mineral distribuídas comercialmente na cidade do Rio de Janeiro* constitui achado que mostra grau indesejável de contaminação, inclusive com a veiculação de amostras de Acanthamoeba, microrganismo cuja ação patogênica ainda é pouco conhecida.

Esses resultados apontam também para as falhas ao nível do processamento e do controle de produtos consumidos em larga escala, quase sempre como opção de quem deseja usar um produto mais limpo e seguro.

SALAZAR, FI. C. et al. [Isolation of free-living amoebae from bottled mineral water]. Rev. Saúde públ., S. Paulo, 16:261-7, 1982.

ABSTRACT: Amoebae of the genera Vahlkampfia, Glaeseria, Acanthamoeba, Filamoeba, Amoeba, Platyamoeba and Hartmanella were isolated from ten different brands of bottled mineral water used in Rio de Janeiro. Of these brands, only one was negative after an incubation period of twenty days, while the others were all positive for free living amoebae. The results are discussed as an indicator of the quality of commercially used mineral water and it is stressed that some of these microorganisms are potentially pathogenic.

UNITERMS: Mineral waters. Water microbiology. Amoeba.

* Um relatório com os resultados obtidos, indicando o nome comercial de cada uma das águas minerais examinadas, foi encaminhado ao Departamento de Vigilância Sanitária da Secretaria de Saúde do Municipio do Rio de Janeiro. 
SALAZAR, H.C. et al. Isolamento de amebas de vida lirre a partir de água mineral engarratada. Rev. Sunde públ., S. Paulo, 16:261-7, 1982.

\section{REFERENCIAS BIBLIOGRAFICAS}

1. BUTT, C.G. Primary amoebic meningoencephalitis. New Engl, J. Med, 274:1473-6, 1966.

2. CAMPOS, R.; GOMES, M.C.O.: PRIGENZI I.S. \& STECCA, J. Meningoencefalite por ameba de vida livre. Apresentaçă. do primeiro caso latino-americano. Rer. Inst. Med. trop. S. Patulo, 19'349-51, 1977

3. CARTER, R.F. Primary amoebic mening. cephalitis: clinical pathological fe:iures of six fatal cases. J. Pathol. Bacteriol. $96: 1-25, \quad 1968$

4. CERVA. L. Experimental infection of labo. ratory animals by the pathogenic Natgleria gruberi strain Vitek. Folia parasitol. Praha, 18:171-6, 1971.

5. CHANG, S.L. Pathogenesis of pathogenic Nuegleria amoeba. Folic parusitol. Praha. 26:195-200. 1979.

6 CORLISS. J.O. Protozoan ecology: a not on its current status. Amer. Zool. 13:145-8. 1973 .

7. CULBERTSON, C.G.: SMITH, J, \& MIN NER, J. Acanthamoeba observations on animal pathogenicity. Science, 127:1506, 1958.

8 CUBERTSON, C.G.: SMITH, J.: COHEN, H. \& MINNER, J. Experimental infection of mice and monkess by Acanthamoebo Amer. J. Pathol, 35:185-97. 1959.

9. CULBERTSON, C.G.. EXSMINGER. P.W \& OVERTON. W.M. The isolation of additional strains of pathogenic Hartmannelli sp. (Acanthamoeba). Proposed culture method for application to biological material. Amer. J. olin. Pathol., $43: 383-7, \quad 1965$

10. CURSONS, R.T.M.; KEYS, E.A.; BROWN, T.J.: LEARMONTH, J.: CAMBELL, C. \& METCALF. P. IgA and primary amoebic meningoencephalitis. Lancet, $1: 223-4.1979$.

11. DANGEARD. P. Etude de la karyokinèse chez Amoeba hyalina sp. nov. Le $B O$. trmist, $\quad$ i:49-83. 1910 .

i2. DUNNEBACKE, T.H. \& SCHUSTER, F.L. An infectious agent associated with amoebas of the genus Nuegleria. $J$. Protosool, $\quad 21 \cdot 327-9, \quad 1974$
13. DU:NNEB:CKE. T. H. \& SCHUSTER, F.L. The nature of a crtopathogenic material present in amoeba of the gen:s Naegleria. Amer. J. trop. Hed. Hyg. $26: 412-21,1977$.

1. TORONDA. A.S. Crescimento de amebas de vida livre em meios semeados com liquido cefalorraquiciano humano (Nota prévia). Rer. paul. Med, 87:140, 1976

i5. FORONDA, A.S. Observaçoes sobre amebas de vida livre potencialmente patogênicas. São Paulo, 1979. [Tese de Doutoramento - Instituto de Ciências Biomédicas USP]

16. FORONDA. A.S. \& FERREIRA, C.S. Cultivo de amebas com as características de Hartmannella - Acunthamoeba e Nae. gleria em infusões de feno (Nota prévia). Rer. patit. Med., 84:55, 1974.

i7. FOWLER, M. \& CARTER, R.F, Acute pyogenic meningitis probably due to Acunthanoebu sp. Brit. med. J.. 2:740-2. 1965

18. GRIFFIN. J.L. Temperature tolerance ot pathogenic and nonpatogenic free-living amoebas. Science, 178:869-70, 1972.

19. TADIN, J.B. \& WILLAERT, E. Mastigamoeba et amibes libres à partir du mucts nasal de ífpreux. Acta leprol., (66/67): $271-3,1977$

20. JADIN, J.B.; HERMANNE, J.: ROBYN, G.; WILlAERT, E.; VAN MAERCKE. $Y$. \& STEVENS, $N$. Trois cases de meningoencephalite amibiene primitive ob. servés a Anrers (Belgique). Ann. Sor. belge Med. trop., 51:255-66, 1971.

21. JADIN, J.B.; WILLAERT, E. \& COM. PERE, F. De la necessité du contrôle biologique des eaux potables. Bull. Acad. N'ct. Med., 156:995-9, 1972.

22. KINGSTON, D. \& WARHURST, D.C. IsOlation of amoebae from the air. $I$. mert. Microbiol., 2:27-36, 1969.

23. MEHTA, A.P. \& GUIRGES, S.Y. Acute amoebic dysentery due to free-living amoebae treated with metronidazole, $J$. trop. Med. Hyg., 82:134-6, 1979.

24. MOLET, B. \& KREMER. M. Techiniques d'etudes et critères morfologiques pour l'identification des amibes libres. Bull. Soc. Sci. rét. Med. comp. 78:215-23, 1976. 
SALAZAR, H.C. et al. Isolamento de amebas de vida livre a partir de água mineral engarrafada. Rev. Saúde públ., S. Paulo, 16:261-\%, 1982.

25. MOURA, H. Amebas de vida livre em piscinas: isolamento, identificação, potencial patogênico. Rio de Janeiro, 1980. [Dissertação de Mestrado - Fundação Oswaldo Cruz]

26. ORTIZ, T.P. \& OCHOTERENA, L.E. Analisis taxonomico de las especies de protozoários encontradas en el água potable de la ciudad de México D.F. Rev. lat. amer. Microbiol., 21 :147-51, 1979.

27. PAGE, F.C. Redefinition of the genus Acanthamoeba with description of three new species. J. Protozool., 14:709-24. 1967.

28. PAGE, F.C. A further study of taxonomic criteria for limax amoebae, with description of new species and a Key to genera. Arch. Protistenk., 116:149-84, 1974.

29. PAGE, F.C. An illustrated key to freshwater and soil amoeba, with notes on cultivation and ecology. Cumbria, Eng., Freshwater Biological Association. 1976. (Scient. publ., 34).

30. PAGE, F.C. A revised classification of the Gymnamoebia (Protozoa: Sarcodina). Zool. J. Linn. Soc., 58:61-77, 1976.

31. PAIX, D.L. Recherche systematique d'amibes dans les eaux minerals. Ann. Soc. belge Med. trop., 54:432-5, 1974

32. RAMOS, R.T.: MOURA, H. \& SALAZAR, H.C. Isolamento de amebas de vida livre de água mineral. In: Congresso Brasileiro de Parasitologia, 5, Rio de Janeiro, 1980. Resumos. Rio de Janeiro, 1980. p. 60.

33. RIVERA, F.; GALVAN, M. ; ROBLES, E.; LEAL, P.; GONZALEZ, L. \& LACY, A.M. Bottled mineral waters polluted by protozoa in México. J. Protozool, 28:54-6, 1981.

34. SCHUSTER, F.L. Intranuclear virus-like bodies in the amoebo-flagellate $N$. gruberi. J. Protozool., 16:724-7, 1969.

35. SINGH, B.N. \& DAS, S.R. Studies of pathogenic and nonpathogenic small free-living amoebas and the bearing of nuclear division on the classification of the order Amoebida. Phil. Trans. roy. Soc., 259:435-76, 1970.

36. THONG, Y.H.; FERRANTE, A.; SHEPHERD, C. \& ROWAN-KELLY, B. Resistence of mice to Naegleria meningoencephalitis transferred by immune serum. Trans. roy. Soc. trop. Med. Hyg., $72: 650-2,1978$.

37. WIILAERT, E. The pathogenicity of free-living amoebae. Rev. Ass. belge Technol. Lab., 4:101-22, 1977.

Recebido para publicasão em 24/11/1981

Aprovado para publicnção em 17/02/1982 